\title{
PRODUCTION PLANNING OF OIL-REFINERY UNITS FOR THE FUTURE FUEL MARKET IN BRAZIL
}

\author{
B. C.MENEZES ${ }^{1}$, L. F. L. MORO ${ }^{1}$, I. E. GROSSMANN ${ }^{2}$, J. D. KELLY ${ }^{3}$, R. A. MEDRONHO ${ }^{4}$, and \\ F. P. PESSOA ${ }^{4}$ \\ ${ }^{1}$ PETROBRAS, Refining Techology, Refining Planning \\ ${ }^{2}$ Carnegie Mellon University, Chemical Engineering Department \\ ${ }^{3}$ Industrial Algorithms, LLC \\ ${ }^{4}$ Federal University of Rio de Janeiro, Chemical Engineering Department \\ Contact e-mail: brencasme@petrobras.com.br
}

\begin{abstract}
RESUMO - The oil industry in Brazil has accounted for US\$ 300 billion in investments over the last 10 years and further expansions are planned in order to supply the needs of the future fuel market in terms of both quantity and quality. This work analyzes the Brazilian fuel production and market scenarios considering the country's planned investments to prevent fuel deficit of around $30 \%$ in 2020. A nonlinear (NLP) operational planning model and a mixed-integer nonlinear (MINLP) investment planning model are proposed to predict the national overall capacity for different oil-refinery units aggregated in one hypothetical large refinery considering four possible future market scenarios. For the multi-refinery case, a phenomenological decomposition heuristic (PDH) method solves separated the quantity and logic variables in a mixed-integer linear (MILP) model, and the quantity and quality variables in an NLP model. Iteratively, the NLP model is restricted by the MILP results.
\end{abstract}

\section{INTRODUCTION}

Production planning is an essential tool in the modern oil-refining industry to predict strategic, tactical and operational settings for refineries and terminals in the oil supply chains. The modeling ofaproduction and logistics problem, including continuous and discrete decisions and considering nonlinearities from processing and blending relations, gives rise toan MINLP model, in which convergence problems and model size escalation constitute the main drawbacks due to limitations in the MINLP solvers, thus reducing the application of these types of models in industrial-sized problems. To overcome these challenges in the strategic planning problem for the future fuel market in Brazil the following models and methods are proposed: first, aggregated multi-site NLP and MINLP refineries models and, second, a decomposition strategy for multi-site refineriesto segregate the quantity-logic-quality (QLQ) phenomena of the MINLP modelin a master MILP problem coupled with slave NLP considering heuristic procedures to integrate both solutions.

Today, as seen in Figure 1, the Brazilian oil-refining industry expansion includes two grassroots refineries under construction and three additional refineries in conceptual project in order to prevent 
fuel deficit of around 30\% in 2020, according to recent forecasts (PETROBRAS, 2013). The national planned investments project an increase of 1,595 kbpd in crude distillation capacity, which includes refineries of PETROBRAS the national oil and energy company, which accounted for $98 \%$ of the total crude distillation capacity in 2013.

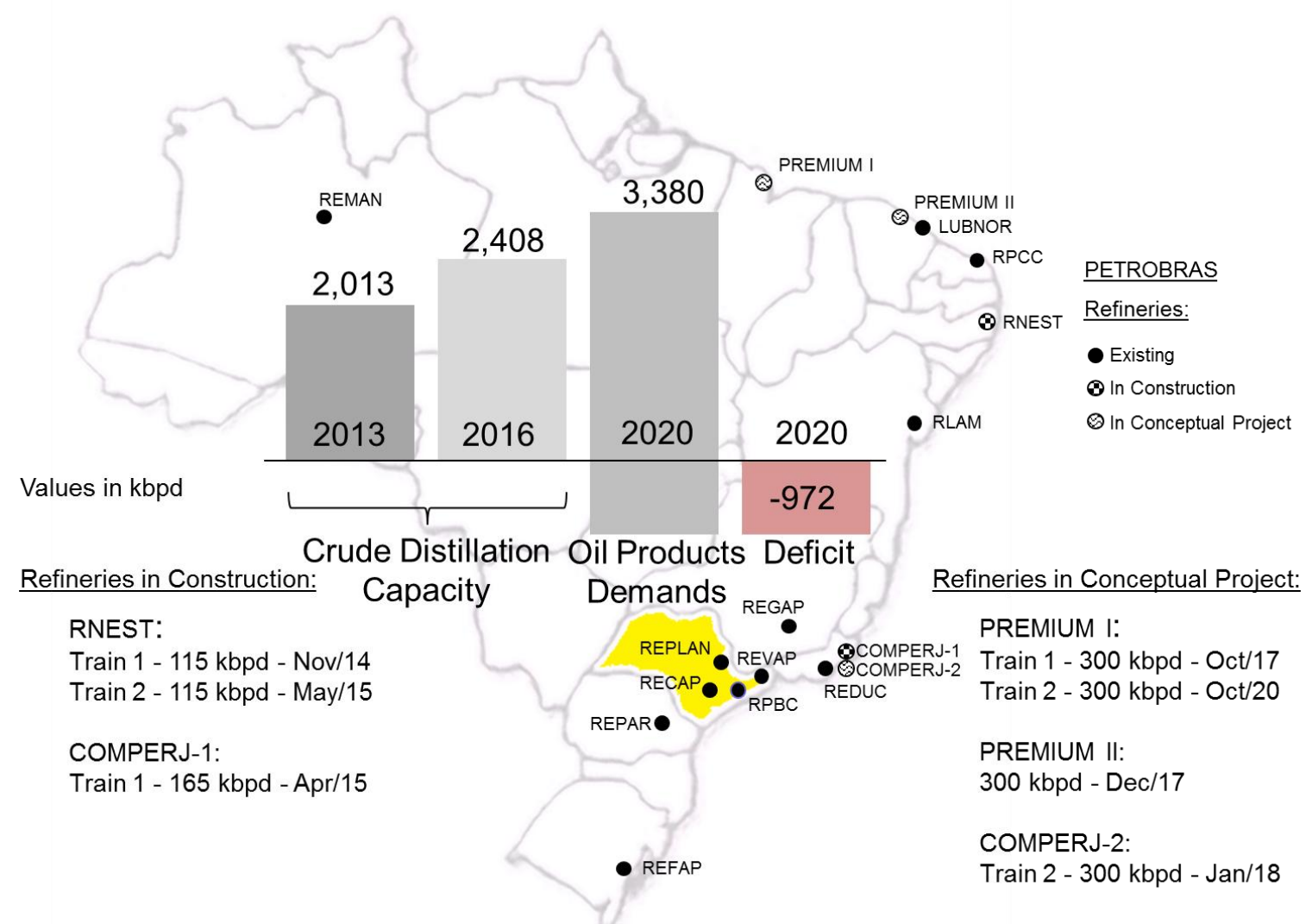

Figure 1 - Oil products deficit of $30 \%$ in 2020 without the refineries in the conceptual project.

Both NLP and MINLP aggregated models predict the national overall capacity expansion of oilrefinery units for possible Brazilian fuel market scenarios in 2020 considering the existing oil-refining assets in 2016, because only after this year the refineries currently under construction will be deployed on-stream. The final overall capacity planning results may indicate alteration in future projects, since the refineries currently in the conceptual phase can still be modified to find the best investment portfolio considering the future official and proposed market scenarios defined in this work.All required data of the Brazilian oil-refining industry such as prices, overall capacity of the units, fuel demand scenarios, and national crude production can be found in Menezes et al. (2014).

For the multi-site approach both the full space MINLP and its phenomenological decomposition model indicatecapacity expansion of the units in two refineries in the Sao Paulo (SP) supply chain (in yellow in Figure 1), currentlycomplemented by the four refineries in this state.

\section{PROBLEM STATEMENT}


The results of the process design scenario-based NLP operational planning model for the national refineries aggregated case are compared with the proposed optimization-based MINLP investment planning model. In the scenario-based model framework the required future capacities of the units are found by the difference between the unit throughputs in 2020 and their capacities in 2016. In this case, large unit throughput upper bounds areconsidered. Regarding the expected and proposed fuel market scenarios for the conceptual projects in 2020, with planned overall capacities different than their demanded throughputs, the projects require retrofits. On the other hand, theMINLP strategic and investment process design synthesis model, which represents discrete decisions as binary variables and takes into account processing and blendingnonlinearities,maximizes the net present value (NPV) to invest in the capacity expansion of units. The fuel demand cases are shown in Figure 2 and its details are found in Menezes et al. (2014).

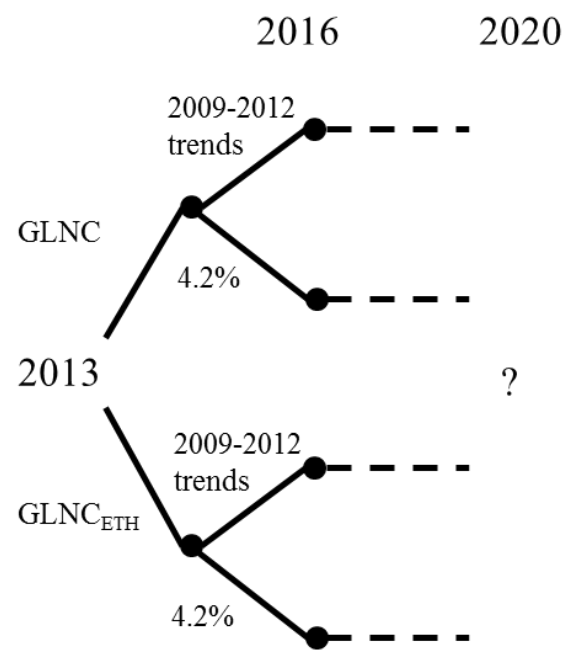

Figure 2 - Four fuel market scenarios in 2016 considered to project the overall refining process scenario in 2020.

Alternatively, for the multi-site refineries case, a phenomenological decomposition heuristic is proposed to solve separately the MILP problem, which dos not consider the nonlinearities from the blending and processing equations, and the NLP problem, where the binary variables from the MILP run are considered fixed. Both, the MINLP and the PDH-MINLP problems are compared for the REPLAN and REVAP in the SP state supply chain.

\section{PRODUCTION PLANNING MODEL}

TheNLP and MILP models are shown in the next subsections. The MINLP case is the combination of both NLP and MILP models. For the aggregated case, one hypothetical refinery called REBRA approximates the national overall capacity for several types of units. Figure 3 shows the refinery framework considered. For the multi-site case, the data regarding the SP state refineriescan be found in Perrisé (2007). 


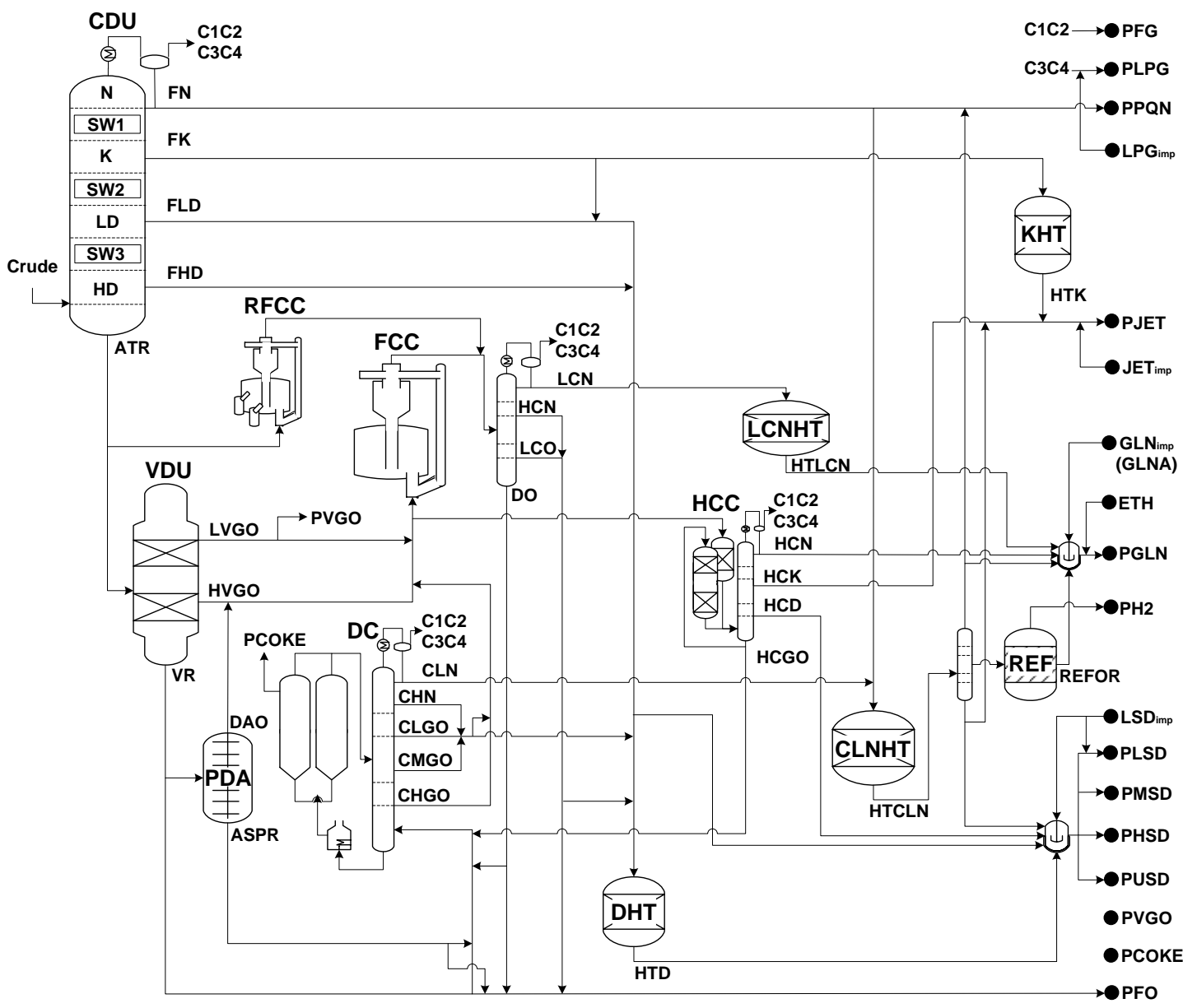

Figure 3 - Hypothetical refinery REBRA.

\subsection{NLP OPERATIONAL PLANNING MODEL}

The single-period NLP operational planning model formulation and the aggregated capacities of the units per type of process indicated in REBRA framework are given in Menezes et al. (2014). The scenario-based approach predicts the overall demanded capacities considering the capacities in the 2016 scenario as the lower bounds for the required capacities in 2020, while the upper bound is arbitrarialy set at $1,000 \mathrm{k} \mathrm{m}^{3} / \mathrm{d}$.

\subsection{MILP INVESTMENT PLANNING MODEL}

Considering the process design synthesis model proposed by Sahinidis et al. (1989), the capacity expansion or installation of the unit uin the refinery $r$ in a certain time $t\left(Q_{r, u, t}\right)$ is actived by the constraint in Equation1. $\mathrm{QN}_{\mathrm{r}, \mathrm{u}, \mathrm{t}}^{\mathrm{L}}$ and $\mathrm{QN}_{\mathrm{r}, \mathrm{u}, \mathrm{t}}^{\mathrm{U}}$ are the lower and upper boundsof the new capacity increment.

$$
\mathrm{yn}_{\mathrm{r}, \mathrm{u}, \mathrm{t}} \mathrm{QN}_{\mathrm{r}, \mathrm{u}, \mathrm{t}}^{\mathrm{L}} \leq \mathrm{QN}_{\mathrm{r}, \mathrm{u}, \mathrm{t}} \leq \mathrm{yn}_{\mathrm{r}, \mathrm{u}, \mathrm{t}} \mathrm{QN}_{\mathrm{r}, \mathrm{u}, \mathrm{t}}^{\mathrm{U}} \quad \forall \mathrm{r}, \mathrm{u}, \mathrm{t}
$$


In the first investment time period, the operational gains derive from the existing units given by their initial capacities $\mathrm{QC}_{\mathrm{r}, \mathrm{u}, \mathrm{t}-1}$. After the project execution interval $\mathrm{t}$, a new capacity can be added to the unit and another profit is found in the operational layer for the following investment time period if the project is approved $\left(\mathrm{yn}_{\mathrm{r}, \mathrm{u}, \mathrm{t}}=1\right)$, as shown in Equation2.

$$
\mathrm{QC}_{\mathrm{r}, \mathrm{u}, \mathrm{t}}=\mathrm{QC}_{\mathrm{r}, \mathrm{u}, \mathrm{t}-1}+\mathrm{QN}_{\mathrm{r}, \mathrm{u}, \mathrm{t}-1} \quad \forall \mathrm{r}, \mathrm{u}, \mathrm{t}
$$

With respect to the capital amount available in each investment time, the liquid cash expensesto build the refining units must be lower than the limit capital for the investments $\left(\mathrm{LCI}_{t}\right)$ as seen in Equation3. $\alpha_{u, t}$ and $\beta_{u, t}$ are the variable and fixed costs per type of unit respectively.

$\sum_{r, u}\left(\alpha_{u, t} Q_{r, u, t}+\beta_{u, t} \mathrm{yn}_{r, u, t}\right) \leq \mathrm{LCI}_{t}$

The NPV objective function is summarized in Equation 4. The calculation of daily operational gains from the scenario-based model (Menezes et al., 2014) is simply multiplied by 365 to generate the annual income. The values are deflated using the future-to-present discount rate considering interest rate (ir) equal to $10 \%$.Taxes (tr) of $25 \%$ and a general price and costs increase rate of $4.2 \%$ p.a. is also considered. The time horizon comprises investment and operational time periods as can be seen in Figure 4.

$$
\begin{aligned}
\max N P V=\sum_{\mathrm{t}} & {\left[365(1-\operatorname{tr}) \sum_{\mathrm{r}, \mathrm{t}_{0}} \frac{\mathrm{CF}_{\text {operational }}}{(1+\mathrm{ir})^{\mathrm{t}_{0}}}\right.} \\
& \left.-\left(\frac{1}{(1+\mathrm{ir})^{\mathrm{t}_{\mathrm{it}}}} \sum_{\mathrm{r}, \mathrm{u}}\left(\alpha_{\mathrm{u}, \mathrm{t}_{\mathrm{it}}} \mathrm{QN}_{\mathrm{r}, \mathrm{u}, \mathrm{t}}+\beta_{\mathrm{u}, \mathrm{t}_{\mathrm{it}}} \mathrm{yn}_{\mathrm{r}, \mathrm{u}, \mathrm{t}}\right)\right)_{\mathrm{t}<\mathrm{t}_{\text {end }}}\right]
\end{aligned}
$$

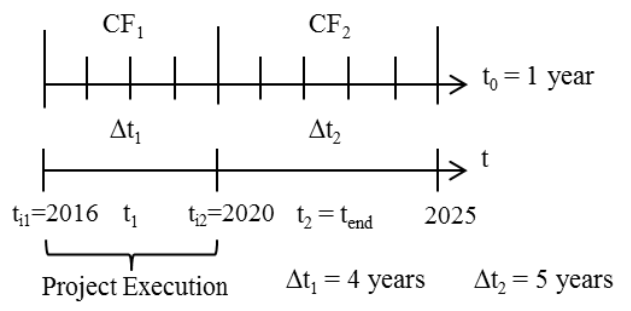

Figure 4 - Investment and operational time periods.

The investment interval $\mathrm{t}$ considers the time necessary to complete the projects construction, while the production from the current assets is simultaneously maintained fixed 
within each fixed interval, varying at $\mathrm{t}_{0}=1$ year. The annual operational cash flow $\left(\mathrm{CF}_{\text {operational }}\right)$ considers that operational settings are kept constant within the investment time period $t$, so that price and demand increments along the operational time period $t_{0}$ are not used to update operational variables within each t. Any additional amounts necessary to supply the yearly market demands inside the interval $t$ are supplied by imports, so that the international market acts as a buffer controlled by the production and demand equilibrium and may point out logistics bottlenecks inside the supply chain.

From planning perspective, the daily profit used here can be considered a snapshot of the daily process gains from the current assets conditions extrapolated to a whole year. Annual variations in prices change the income weights in the NPV objective at every $t_{0}$ step, even with the MINLP model solution being performed at every step t. The expenses with extra imports to match the yearly market demands are assumed to be equivalent to the increment in annual fuel sales gains. Fortunately, these extra imports have little or no influence in the NPV-based decision.

\section{PHENOMENOLOGICAL DECOMPOSITION HEURISTICS}

The phenomenological decomposition heuristics (PDH) decomposethe QLQ phenomena of the MINLP problems into two simpler sub-models, namely logistics (quantity and logic) and quality(quantity and quality) optimizations, QL and QQ, respectively. The logistics model named INVEST solves for quantity and logic variables (project selection) subject to quantity and logic balances and constraints, while the quality optimization OPERA solves for quantity and quality variables subject to quantity and quality balances and constraints after the logic variables have been fixed at the values obtained from the solution of the logistics optimization. A warm-start phase is initially performed to obtain initial values for the MILP master problem as seen in Figure 5.

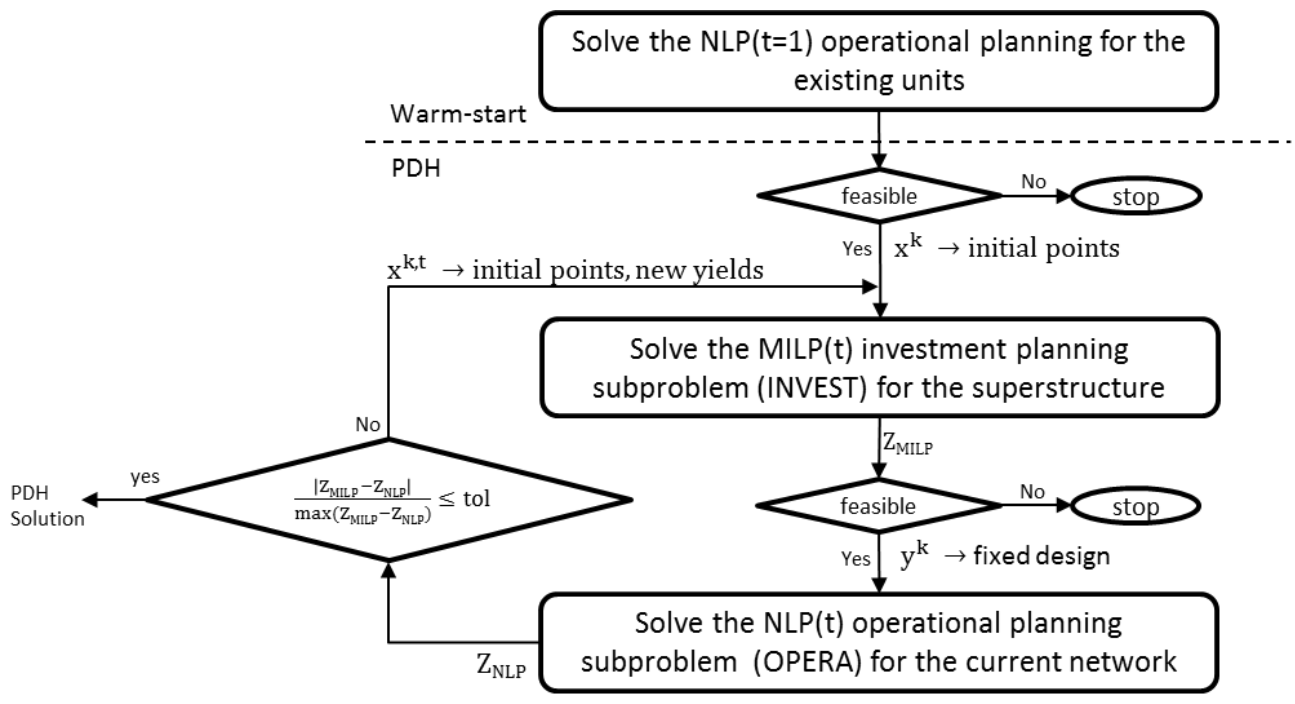

Figure 5 - Flowchart for the warm-start and PDH algorithm. 


\section{RESULTS}

The aggregated case results for REBRA are shown in Table 1 and the decomposed case results for the REPLAN and REVAP in the SP state in Table 2. All case studies were implemented in the GAMS modeling languageversion 23.9.3 on an Intel Core 2 Duo (3.00 GHz, 16.0 GB of RAM).

Table 1 - NLP and MINLP results forthe unit capacities in REBRA in 2020

\begin{tabular}{|c|c|c|c|c|c|c|c|c|c|c|}
\hline \multirow[b]{4}{*}{ unit (u) } & \multirow[b]{4}{*}{2016} & \multicolumn{8}{|c|}{2020 (Results) } & \multirow{4}{*}{$\begin{array}{c}2020 \text { (Planned) } \\
\text { Conceptual } \\
\text { Project })\end{array}$} \\
\hline & & \multicolumn{4}{|c|}{ NLP } & \multicolumn{4}{|c|}{ MINLP } & \\
\hline & & \multicolumn{2}{|c|}{ 2009-2012 trends } & \multicolumn{2}{|c|}{$4.2 \%$ p.a. } & \multicolumn{2}{|c|}{ 2009-2012 trends } & \multicolumn{2}{|c|}{$4.2 \%$ p.a. } & \\
\hline & & GLNC & $\mathrm{GLNC}_{\mathrm{ETH}}$ & GLNC & $\mathrm{GLNC}_{\mathrm{ETH}}$ & GLNC & GLNC $_{\text {ETH }}$ & GLNC & $\mathrm{GLNC}_{\mathrm{ETH}}$ & \\
\hline $\mathrm{CDU}$ & 372 & 549.1 & 550.0 & 482.4 & 507.3 & 590.5 & 553.3 & 492.0 & 467.2 & 536 \\
\hline VDU & 153 & 242.8 & 265.0 & 226.8 & 246.7 & 204.5 & 266.9 & 205.5 & 218.2 & 260 \\
\hline FCC & 76 & 76.0 & 76.0 & 79.2 & 76.0 & 76.0 & 90.9 & 76.0 & 76.0 & 76 \\
\hline $\mathrm{HCC}$ & 10 & 91.5 & 98.3 & 68.4 & 68.4 & 53.2 & 75.6 & 54.0 & 93.4 & 73 \\
\hline RFCC & 22 & 43.7 & 22.0 & 22.0 & 22.0 & 105.5 & 22.0 & 48.8 & 22.0 & 22 \\
\hline DC & 50 & 146.2 & 104.7 & 106.0 & 56.3 & 79.8 & 92.8 & 80.5 & 75.6 & 100 \\
\hline KHT & 15 & 19.0 & 17.8 & 15.0 & 15.0 & 25.9 & 18.9 & 17.6 & 15.0 & 15 \\
\hline D2HT & 68 & 122.4 & 120.0 & 109.4 & 97.2 & 125.3 & 117.3 & 111.0 & 96.1 & 135 \\
\hline LCNHT & 54 & 64.6 & 52.9 & 54.6 & 52.9 & 98.0 & 62.1 & 67.4 & 54.0 & 54 \\
\hline CLNHT & 34 & 81.9 & 60.8 & 61.8 & 37.0 & 48.7 & 55.2 & 49.1 & 46.6 & 62 \\
\hline FRAC3 & 34 & 81.9 & 60.8 & 61.8 & 37.0 & 48.7 & 55.2 & 49.1 & 46.6 & 62 \\
\hline REF & 12 & 37.2 & 28.6 & 27.7 & 16.4 & 18.1 & 24.6 & 20.4 & 22.7 & 12 \\
\hline \multicolumn{2}{|c|}{ capital investment (bi US\$) } & 34.7730 & 28.2714 & 22.5300 & 14.7968 & 25.0000 & 24.5079 & 19.1699 & 21.1708 & 23.1563 \\
\hline \multicolumn{2}{|c|}{ NPV (bi US\$) } & - & - & - & - & 8.8189 & 5.5455 & 11.6236 & 6.6885 & \\
\hline \multicolumn{2}{|c|}{ profit (mi US\$) } & 38.491 & 29.081 & 27.384 & 16.046 & 27.123 & 23.100 & 22.747 & 20.701 & \\
\hline \multicolumn{2}{|c|}{ no. of equations } & \multicolumn{4}{|c|}{406} & \multicolumn{4}{|c|}{1019} & \\
\hline \multicolumn{2}{|c|}{ no. of continuous variables } & \multicolumn{4}{|c|}{460} & \multicolumn{4}{|c|}{1127} & \\
\hline \multicolumn{2}{|c|}{ no. of discrete variables } & \multicolumn{4}{|c|}{-} & \multicolumn{4}{|c|}{12} & \\
\hline \multicolumn{2}{|c|}{ no. of non zero elements } & \multicolumn{4}{|c|}{1772} & \multicolumn{4}{|c|}{4463} & \\
\hline \multicolumn{2}{|c|}{ no. of non linear elements } & \multicolumn{4}{|c|}{1061} & \multicolumn{4}{|c|}{2552} & \\
\hline CPU (s) & & 0.561 & 0.375 & 0.530 & 0.484 & 0.826 & 7.377 & 1.080 & 0.936 & \\
\hline
\end{tabular}

Table 2 -MINLP and PDH-MINLP (MILP+NLP)results for two SP state refineries in 2020.

\begin{tabular}{llcccc} 
Existing & \multicolumn{3}{c}{ MINLP } & \multicolumn{2}{c}{ PDH (MILP + NLP) } \\
REPLAN & REVAP & REPLAN & REVAP & REPLAN & REVAP \\
CDU.(1,2) & CDU.1 & \multicolumn{4}{c}{ Expansion } \\
VDU.(1,2) & VDU.1 & CDU & FCC & FCC & CDU \\
FCC. $(1,2)$ & FCC.1 & FCC & LCNHT & LCNHT & VDU
\end{tabular}




\begin{tabular}{|c|c|c|c|c|c|}
\hline DC. $(1,2)$ & DC.1 & LCNHT & CLNHT & CLNHT & FCC \\
\hline LCNHT.1 & PDA.1 & CLNHT & KHT & & LCNHT \\
\hline CLNHT.1 & LCNHT.1 & KHT & DHT & & CLNHT \\
\hline DHT. $(1,2,3)$ & CLNHT.1 & DHT & & & KHT \\
\hline \multirow[t]{3}{*}{ REF.1 } & KHT.(1,2) & \multicolumn{4}{|c|}{ Installation } \\
\hline & DHT.(1,2) & & $\mathrm{CDU}$ & \multirow[t]{2}{*}{$\mathrm{CDU}$} & \\
\hline & REF.1 & & VDU & & \\
\hline \multicolumn{2}{|c|}{ capital investment (bi US\$) } & 3.20 & & \multicolumn{2}{|c|}{2.87} \\
\hline \multicolumn{2}{|c|}{ NPV (bi US\$) } & 12.90 & & \multicolumn{2}{|c|}{10.37} \\
\hline \multicolumn{2}{|c|}{ no. of equations } & 3,806 & & \multicolumn{2}{|c|}{$1,917+3,152$} \\
\hline \multicolumn{2}{|c|}{ no. of continuous variables } & 4,551 & & \multicolumn{2}{|c|}{$2,615+4,124$} \\
\hline \multicolumn{2}{|c|}{ no. of discrete variables } & 198 & & \multicolumn{2}{|c|}{198} \\
\hline \multicolumn{2}{|c|}{ no. of non zero elements } & 16,716 & & \multicolumn{2}{|c|}{$7,009+14,821$} \\
\hline \multicolumn{2}{|c|}{ no. of non linear elements } & 8,368 & & \multicolumn{2}{|c|}{8,184} \\
\hline \multicolumn{2}{|l|}{ CPU (s) } & 15.22 & & \multicolumn{2}{|c|}{$0.11+1.31$} \\
\hline
\end{tabular}

\section{CONCLUSION}

The NLP and MINLP models results for the four demand scenarios in 2020 indicate the necessity to reevaluate the strategic decisions to supply the future fuel market needs.Comparing the results obtained with both the NLP and the MINLP methodologies, the former is incomplete because does not take into account the investment constraints which in turn leaded to very expensive and unrealistic design by decrease the capacity of separation units (CDU and VDU) and by increase the capacity of cracking units (HCC and DC). The MINLP process design synthesis model presented lower capital investment needed when compared with the official scenarios $(4.2 \%$, GLNC).

The multi-site case including the two refineries in the SP state compares the MINLP and PDH-MINLP approaches in terms of size and solution. As seen, the decomposition method yielded lower NPV, but with lower capital investment.

\section{REFERENCES}

MENEZES, B. C.; MORO, L. F. L.; LIN, W. O.; MEDRONHO, R. A.; PESSOA, F. P. Nonlinear Production Planning of Oil-Refinery Units for the Future Fuel Market in Brazil: Process Design Scenario-Based Model. Ind. Eng. Chem. Res., v. 52, p. 4352-4365, 2014.

PERRISÉ, J. B. Oil-Refining Evolution in Brazil. M.D. Thesis, State University of Rio de Janeiro, August 2007.

PETROBRAS. Business Plan 2013-2017. Rio de Janeiro, March 2013.

SAHINIDIS, N. V.; GROSSMANN, I. E.; FORNARI, R. E.; CHATHRATHI, M. Optimization Model for Long Range Planning in the Chemical Industry. Comput. Chem. Eng.,v. 13(9), p. 1049-1063, 1989. 